\title{
Research on the Development Law of Carbonate Reservoir Cracks in Niuxintuo West Oilfield
}

\author{
Shu-Xia WANG
}

\author{
Liaohe Oilfield of China Petroleum Liaoning Panjin, Daqing, Heilongjaing Province, China \\ wangsx_2016@163.com
}

Keywords: core analysis, logging well identification, fracture prediction, carbonate rock, Niuxintuo.

\begin{abstract}
For the geological characteristics of carbonate reservoirs in West Niuxintuo Oilfield, using core description, well logging fracture identification,3DMOVE fracture prediction and other new technology, the inside story of carbonate reservoir is found out under the guidance of geology, well logging, petrology and geological mechanics and other disciplines theory. On the whole, reservoir composed mainly by structural fractures has roughly three development directions that are NNW. The crack on plane mainly developed in four regions, heterogeneity of crack development in the longitudinal direction is strong. The dolomite reservoir is more developed. Research on the law of cracks provides the basis for block development and deployment of the next step adjustment.
\end{abstract}

\section{Introduction}

Niuxintuo Oilfield which is an important third-level tectonic element in the oilfield is located at the north of Liaohe basin in west depression. The upper Niuxintuo oil reservoir rocks is mainly constituted by coarse clastic rocks of proximal fan and carbonate rocks of lacustrine phase chemical deposition that developed from the basis of the basilar uplift during the early time of the fourth substrate of the Shahejie Age. At present, clastic rocks have carried out water-flooding absolutely and have a good development effect, but the carbonate rock in the west is not at the state of mobilization because of no clear understanding of reservoir physical property and the law of crack development. This paper takes a research on the carbonate reservoir structure, lithology and fracture characteristics in order to have a clear understanding of the law of crack development and lay a foundation for the further research.

\section{Geological Situations}

Located on the Liaohe Oilfield construction Niuxintuo faulted anticline Niuxintuo fault zone north of the southern tip of western sag, bottom-up development of the Archean buried hill formation, Mesozoic red beds, Lower Tertiary Shahejie beef heart Tuo, soaring, Dujiatai, sand and Guantao three sections. Niuxintuo reservoir is the purposes layer of major development ,It is divided into seven sandstone series in the longitudinal direction, west carbonate reservoir of the upper 1-3 sandstone series developed, oil-bearing area is $2.6 \mathrm{~km} 2$,petroleum geological reserves is $340 \times 104 \mathrm{t}$, reservoir type is fractured massive permeability oil reservoir. The depth of reservoir is $1750-1980 \mathrm{~m}$, average effective thickness is $35.7 \mathrm{~m}$, average porosity is $11.3 \%$, average penetrance is $26.7 \times 10-3 \mu \mathrm{m}$, the density of crude oil is $0.91 \mathrm{~g} / \mathrm{cm} 3$, the viscosity of ground dead oil whose temperature is $50^{\circ} \mathrm{C}$ is $1019 \mathrm{mPa} \cdot \mathrm{s}$.

\section{Structure of Reservoir and Characteristics of Petrology}

\section{Structural Feature}

Researches on structural feature provide the background of reliable geological structure for crack research. Using combination of drilling data and earthquake, finding electrical characteristics of contrast marker layer and oil groups, on this basis of sedimentary cycle, according to three principles: hierarchical control, from big to small, step by step, carrying out fine stratigraphic contrast, on this basis, making the map of small layer structure. On the whole, structural form of 
Niuxintuo reservoir which is along NE SW is faulted nose structure ,the axial line of the faulted nose structure roughly is along Tuo 25-37 Tuo 39-37, the length is 4000m from south to north, structural area is about $16 \mathrm{~km} 2$. Construction highness which is located at the northeast is near Tuo 40-128 Tuo38-38 .Closure is about $1000 \mathrm{~m}$, construction highness whose angle of bedding is $20^{\circ} \sim$ $30^{\circ}$ plunges to southwest. Five faults developed in the oil filed, four of them are border faults which have a good plugged effect on oil gas and their amplitude is more than 150m. There are three terminal faults whose amplitude is 50 100m internally, their sealing is worse(Fig 1).
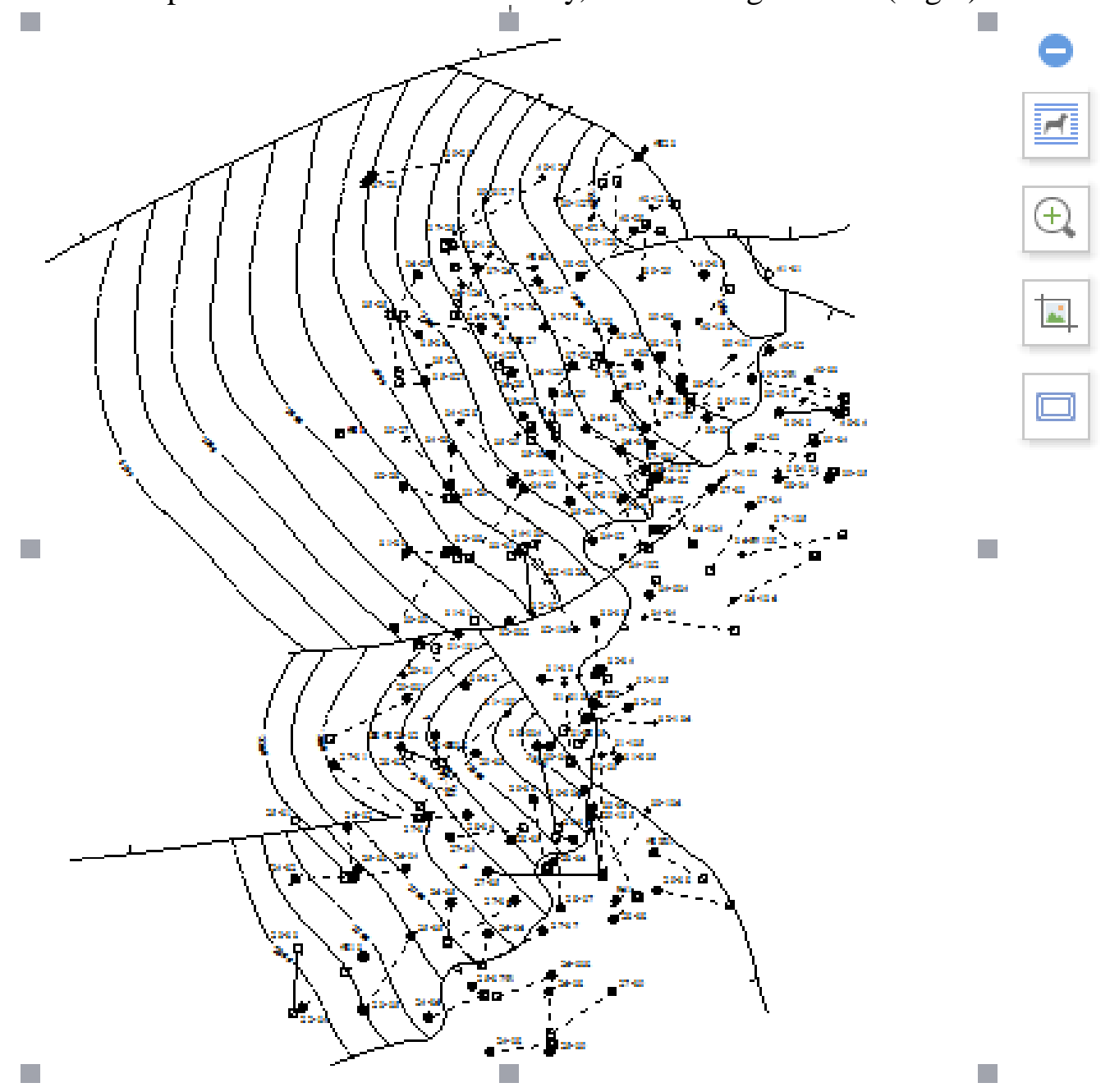

Fig.1 The map of Niuxintuo carbonate rock reservoir roof boundary

\section{Characteristics of Petrology}

Dividing Niuxintuo carbonate rock reservoir into two types by observing core, analyzing rock section and x-ray diffraction: argillaceous dolomite and dolomite, argillaceous dolomite is major. The argillaceous dolomite whose structure is dense block and lamellar is light grey and dark grey, its content is 50\% 90\%,crystalline grain is smaller than $3 \mathrm{~mm}$,the major structural composition is dolomite, mineral composition major is dolomite whose content is 50\% 90\%, content of quartz and feldspar which is $10 \%$ 35\% is fewer than dolomite, there are a few pyrite, zeolite, siderite. Dolomite whose structural composition is dolomite, it is light gray, its structures are lamellar and brecciated. Compared with argillaceous dolomite, dolomite has more mud crystal which is more than $80 \%$,rock constituents major is dolomite, its content is more than $90 \%$, there are a little quartz, feldspar and pyrite.(Fig2) 


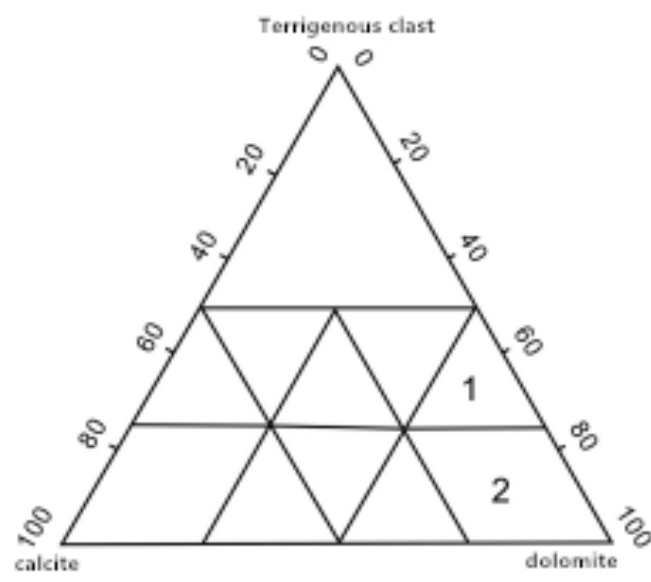

1: argillaceous dolomite

2: dolomite

Fig.2 Niu xintuo Carbonate rock content classification triangle

\section{Research on law of reservoir fracture development}

Crack description which plays an important role in determining the developmental plan of oil field is the foundation of studying crack formation and distribution of carbonate reservoir, it is also the foundation of evaluating different crack effect, analyzing crack effectively and predicting the system of fluid flowing in the underground.

\section{Description of Core Crack}

We can obtain the characteristics of crack by observing and counting 58 samples and 628 cracks as follows:

(1)Azimuth and inclination of cracks. In this area, the strata developed in parallel bedding, bedding plane is almost perpendicular to the core cylinder, layer substantially is equal to the horizontal plane. Therefore, the occurrence of crack can be distinguished according to relationship of crack and bedding. It can be divided into three directions according to core macro and the observation of cast slice: parallel to the bedding, perpendicular to the bedding, oblique to bedding, the angle of oblique crack and bedding.

(2)Density of crack. It is restricted by rock type and tectonic stress etc. In addition, density of crack normally adopts linear density, which means that number of cracks measured on a per unit length. According to the statistical results, density of crack of argillaceous dolomite is small, normally 8 to 40 articles / $\mathrm{m}$, average 16.2 articles / $\mathrm{m}$; density of dolomite crack is bigger, normally 20 to 200 articles / $\mathrm{m}$, average 43.2 articles / $\mathrm{m}$.

(3)Crack length and opening. Affected by fractured carbonate reservoirs, core is shattered, length of crack is difficult to measure. Opening of core crack is normally 0.5 to $1 \mathrm{~mm}$, average $0.72 \mathrm{~mm}$.

(4)Fracture stage.Among the three groups cracks, vertical cracks cut the horizontal cracks, oblique crack cuts the vertical crack, oblique cracks are at least two stages, they are filled by dolomites early time and are not filled later period, therefore, we can infer that horizontal cracks are earlier than vertical cracks,vertical cracks are earlier than oblique cracks.

(5)Characteristics of crack filling. Fillers in the cracks are mainly dolomite, local layer sections are filled by dolomite and zeolite, filled degree of the upper crack dolomite is high, compaction percentage reaches $98 \%$ to $100 \%$, the cracks in the middle and lower part are filled with dolomite stone, others are half filled or not filled with dolomite. There are so little difference among crack compaction percentage of different occurrences. 
Tab. 1 Statistics of carbonate rock fracture development in Tuo 32-34

\begin{tabular}{ccccccc}
\hline \multirow{2}{*}{$\begin{array}{c}\text { Wells } \\
/ \mathrm{m}\end{array}$} & \multicolumn{2}{c}{ Parallel to the bedding } & \multicolumn{2}{c}{ Vertical to the bedding } & \multicolumn{2}{c}{ Oblique to the bedding } \\
\cline { 2 - 7 } & $\begin{array}{c}\text { frequency } \\
/\left(\mathrm{A} \cdot \mathrm{m}^{-1}\right)\end{array}$ & $\begin{array}{c}\text { seam width } \\
\text { frequency }\end{array}$ & $\begin{array}{c}\text { seam width } \\
/(\mathrm{mm}\end{array}$ & $\begin{array}{c}\text { frequency } \\
/\left(\mathrm{A} \cdot \mathrm{m}^{-1}\right)\end{array}$ & $\begin{array}{c}\text { seam width } \\
/ \mathrm{mm}\end{array}$ \\
\hline $1745.5-1746.5$ & 22 & 1 & 1 & 0.5 & 18 & 1 \\
$1746.5-1747.2$ & 70 & $0.3 \sim 3$ & 1 & & 18 & $0.2 \sim 2$ \\
$1747.2-1749.2$ & 22 & 1 & 40 & $0.5 \sim 1$ & 0 & $1 \sim 3.0$ \\
$1749.2-1750.0$ & 28 & & 36 & & 82 & 0.5 \\
$1750.0-1757.25$ & 1 & & 1 & & 67 & $0.5 \sim 1$ \\
$1757.75-1762.75$ & 0 & & 58 & & 2 & 0.5 \\
Average & 24 & 1 & 28 & 0.5 & 33 & 1 \\
\hline
\end{tabular}

\section{Fracture Log Identification}

Description of core observation is the most intuitive and effective way to study reservoir fractures. However, out of economic considerations, the amount of any oilfield coring wells is limited and discontinuous. In recent years, using well logging method to evaluate fractured reservoir gradually becomes a more complete technology, besides, it has become an important means to explore and developed fractured reservoirs.

\section{Conventional Fracture Log Identification}

Based on the different geophysical characteristics of fractures and bedrock, it is possible to cause different logging responses to identify and analyze fractures. According to the characteristics of carbonate reservoirs in this area, there are obvious low-resistance anomalies in the fractured zone, and the curve shapes are high and low, and undulating, and the lateral trace of the low-angle fracture development section is small Negative difference or even no difference, high-angle fracture segment bilateral curve shows a positive difference; The acoustic time difference log is insensitive to the high-angle fractures. For oblique, horizontal or net-like seams, cyclic jumps occur in a short jagged form; In radioactive logging, the compensated neutrons show high neutron porosity degrees, low neutron gamma, no uranium gamma and natural gamma apparent amplitude difference [4].

According to the characteristics of the response curves of 38 wells in carbonate reservoirs of Niuxintuo oil reservoir, the corresponding fracture index is established. Then, the probability of fracture is converted into a quantitative comprehensive probability model to calculate the probability of comprehensive fracture. The size of the comprehensive probability reflects the degree of fracture development. Obtaining the developmental characteristics of reservoir fractures by calculating: (1) The heterogeneity of growth of vertical crack is strong, there are several obsolete stages of cracks in each well, even dense layers; (2) The degree of fracture development is basically the same. The oblique high angle fractures are the main factors, but the upper cracks are filled with dolomite, part of the lower part of the cracks are filled with dolomite, the degree of fracture development has a certain relationship with lithology, cracks of dolomite developed better.

\section{Identification of Dip Logging Crack}

Dip logging crack is one of the most effective way to study natural cracks. DCA that is a mark of the identification of cracks will display after calculating the original record of measurement of formation dip, finding the difference of conductivity readings between the electrode plates on the wells which is determined by the allowable range of contrast movement of curves and adjacent two plates, superimposing the positive difference on the azimuth curve of the plate. DCA results can directly show the direction of the crack.

Using high resolution dip meter processing 15 wells, the results show that the crack orientation roughly is three groups, NNW is the main direction, NE to the second, third group is close to EW. The fracture direction obtained by this method is consistent with the results of core observation and 
well logging identification. The cracks of Zhang 1 and Tuo27-39 are far away from faults developed well in the north and east, besides, cracks in the west and east also developed well.

\section{Crack Prediction}

Research on core and logging fracture only can use well point data to study crack in the reservoir, the advantage of these methods is that it is more accurate and reliable to describe the fracture characterization parameters. The disadvantage is that the predictive ability is poor and the predictive results of reservoir fracture distribution can't be obtained, so using the method of crack inversion to describe and predict cracks has played more and more important role.

We use the more advanced 3DMOVE crack prediction software at home and abroad to predict. The software application structurally forward and inverse methods, through the formation of tectonic development history of inversion and forward to each issue shall be calculated variable tectonic movements produced by the formation. Then using dependent variable as main control parameter, At the same time, considering the formation thickness, lithology, fracture development direction and other parameters, the relative enrichment zone and the main development direction of the fracture development are predicted, Using the stochastic simulation algorithm of multi parameter control in the calculation process, the parameters of the crack growth are mainly controlled by the obtained strain and curvature, the seismic attributes (such as coherence, amplitude, etc.) and the geological properties (such as porosity, etc.) are used to constrain stochastic simulation algorithm. This time the prediction of Niuxintuo reservoir carbonate fracture mainly use oblique cut. From predictive results, we can see that development direction of fracture prediction is consistent with the core description and DCA treatment, it is mainly distributed in Tuo 39-29 wells, Tuo 37-131 wells, Tuo 35-29 wells Tuo 39-0127 wells, Tuo 31-33 wells Tuo 27-33 wells(Figure 3).

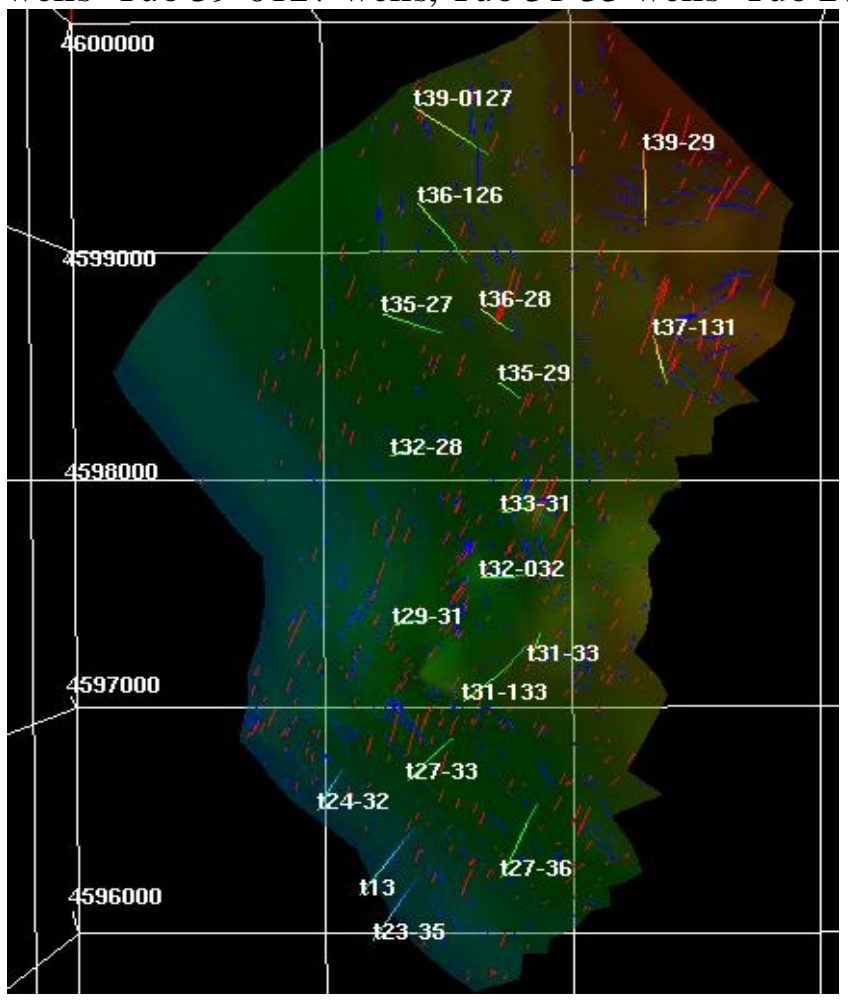

Fig.3 The fractured prediction map of carbonate rock reservoir in Niuxintuo

\section{Effectiveness Analysis of Fracture}

About fissured reservoir, as to the fracture is connected, it is the most favorable storage space. So only by finding out spatial distribution of effective fractures, can we provide the most effective basis for the follow-up oilfield development. In the study of Niuxintuo carbonate rock reservoir fracture, According to the known three-dimensional stress state, the trend of crack expansion, 
sliding trend and leakage factor were calculated, the greater the value of the three values, the greater the probability of connectivity, so as to analyze the effectiveness of cracks. Through the calculation of the three main evaluation parameters, the results show that sliding trend, expansion trend and leakage capacity are strong in Tuo 27-33 31-33 well line, Tuo 37-131 well, Tuo 39-29 well area, and they are effective parts of the development of fractures. While Tuo 35-29 well to Tuo 39-0127 well line fracture development well, but the effective fracture development is relatively poor.

\section{Conclusion}

(1)Structure,lithology and core analysis are the basis of fracture research; Logging identification is an important means of fracture research; Tectonic stress inversion is an effective way to predict fracture between wells.

(2)Niuxintuo carbonate rock reservoirs develop three groups of cracks meanly, such as NNW, $\mathrm{NE}$, and nearly EW, and the most important is NNW; On flat surface cracks are mainly distributed in the Tuo 39-29 well, Tuo 37-131 well, Tuo 35-29 well Tuo 39-0127 Well, Tuo 27-33 Well Tuo 31-33 wells line; The fractures of the vertical heterogeneity are strong, development degree has a certain relationship with lithology, the fractures of dolomite rock are further developed.

(3)The study of fracture development regular pattern provides sufficient basis for the exploration of high quality reservoirs and reasonable adjustment of development.

\section{References}

[1] Zhang Houfu, et al. Petroleum geology [M] Beijing Petroleum Industry Press, 1999: 133 164.

[2] Bai Songzhang. Preliminary discussion about double fractured carbonate reservoirs of flow characteristics. Buried Hill, 1989, 3(2):11 13 .

[3] Huang Puqiong et al. Study on the method of quantitative analysis of fissure volume density in reservoirs. Seismology and Geology.1999, 21(3):261 267.

[4] Cao Jiatai .et al. Comprehensive of logging well data [M] Beijing: Petroleum Industry Press, 2002.

[5] Chen Bo et al. Numerical simulation technique for structures in reservoir case studies. Acta Petrolei Sinica, 1998, 19(4):50 54.

[6] Huang Suwang. The reservoir description of Qijia buried hill fractured basement and the study on deploy of surrounding area. University of Petroleum, 1998. 